\title{
Tracing Context in the Discourse of the Media: Features of Language-in-Use in the British Press
}

\author{
María José González Rodríguez \\ University of La Laguna \\ majgonza@ull.es
}

\begin{abstract}
The language of newspapers is usually explored by linguists because it is undoubtedly the most widely genre read in Western countries. Systemic linguistics provides useful tools for analysing newswriting, identifying grammatical and lexical elements that are functional for achieving particular purposes in media discourse. Using Halliday's approach to context (1978, 1985a, 1989a, 1989b, 1989c, 1994), and Halliday and Matthiessen, 2004, the aim of this article is to explore to what extent situational and cultural context determines the linguistic features used in two British national newspapers, The Times and The Sun. More specifically, through a systemic functional approach to language, I illustrate how newswriting is itself structured for a particular use and how register variables impact into that language use.
\end{abstract}

\section{Introduction}

Since the notion of register proposes an intimate relationship between text and context so that one can only be explained by reference to the other, its principal concern is the study of the use of language for communication in context. The context of situation can be interpreted by means of a conceptual framework using the terms field, tenor and mode of discourse (Halliday, 1978, 1985a, 1989a, 1989b, 1989c, 1994; Halliday and Matthiessen, 2004). These abstract components of the context of situation serve to understand the environment in which meanings are exchanged.

In this paper I adopt a functional approach to the study of newspaper stories exploring how they are systematically patterned towards important social ends. From the analysis of 
a set of news reports from the British national newspapers The Times and The Sun, it is examined the association between the situational variables field, tenor and mode and predictable linguistic patterns, in order to explore the social context applicable to news discourse.

\section{The data}

The British national press provides a variety of political views, interests and levels of education. National newspapers are considered quality or popular papers on the basis of differences in style and content. Quality newspapers, which are broadsheet in format, are directed at readers who want full information on a wide range of news and current affairs and are prepared to spend a considerable amount of time reading it. Popular or tabloid newspapers appeal to people who want news of a more entertaining character, presented in a more concise form and with ample illustrations. The more popular tabloid papers tend to appeal to those who want issues with more human interest, aiming for maximum eyecatching impact in the fewest possible words, and they generally contain a larger number of photographs.

I will approach the differences between stories in the British quality and popular press by dealing with hard news. These are news stories of considerable public events which have significance for large numbers of people and tend to be very timely and immediate. According to Bell (1991), all the press news are basically divided into two categories: hard news and soft news. By hard news he is defining their staple product: reports of accidents, conflicts, crimes, announcements, discoveries and other events which have occurred or come to light since the previous issue of their paper. And "the opposite of hard news is soft news, which is not time-bound to immediacy" (Bell, 1991: 14).

In the ensuing discussion the description is illustrated throughout with the study of concrete examples published in the quality daily The Times and in the popular The Sun. The corpus comprises a selection of 24 reports in each newspaper on a common topic, the War on Iraq, during a few crucial days in March and April 2003 before the American final attack on the capital. For this research, the data collected span a short period of 28 days, from $24^{\text {th }}$ March to $20^{\text {th }}$ April. Due to the limited scope of this article, most references will be made here to day March $27^{\text {th }}$, when an important event came to the limelight of international scene: the execution of two British soldiers by Iraqi forces and the decision of Al Jazeera television to show the dead prisoners of the war.

The reports were taken from the respective websites of the two newspapers (www.thetimes.co.uk and www.thesun.co.uk). All references in the analysis section below will be to these web-based archives. A sample of the study was checked against the hardcopy versions of the two newspapers in order to show that, although the format was different, the textual content was the same in the two versions. 


\section{Theoretical background}

The framework that will be taken up in my analysis adopts a perspective in which newspaper language is studied as a communicating tool. In this approach, news communicates more than just inert information, and part of the meaning of the news is derived from the social structure in which it is uttered. This approach also involves the assumption that meaning is a product of interaction. One interesting observation that emerges from this is the fact that news means nothing at all at the time it is printed; it has to be read. And the same social determinants that are at work in news itself will also be at work when one reads it. In this view, I agree with Fairclough (1995: 65, 1998: 142-162) when he claims that it is important both for linguists to be sensitive to how discourse is shaped by and helps to shape social structures and relations, and for sociologists to be sensitive to how social structures and relations are instantiated in the fine detail of daily social practices, including discourse.

The focus on how language functions in its immensely varied range of social contexts has guided numerous studies on discourse. The perspective from which I have analysed the corpus is included in the line of studies advocated by Mardh, 1980; Simon-Vanderbergen, 1981; Haan, 1987; Sperber and Wilson, 1995; Bloor and Bloor, 1995, 2004; Thompson, 1996, 2004; López Maestre, 1997a, 1997b, 1998, 1999; Ghadessy, 1999; Gómez Guinovart and Pérez Guerra, 2000; González Rodriguez, 2003, 2004; Chafe, 2003; Martin and Rose, 2003; Allan, 2004 (inter alia). This perspective is multidisciplinary and combines an analysis of the linguistic, cognitive, social and/or cultural aspects of the texts in context. In this approach, I adopt a dynamic perspective in which language is a tool for social interaction to argue for systematic correlations between the organization of language itself and specific contextual features, and to explore to what extent situational factors determine and influence the linguistic pattern used in them.

\section{Register theory}

The theoretical model considered here, namely a model about language use, corresponds to the sociosemiotic model of language developed by Halliday $(1978,1985 \mathrm{a}, 1989 \mathrm{a}$, $1989 \mathrm{~b}, 1989 \mathrm{c}, 1994$ ), and Halliday and Matthiessen (2004). This model will be outlined in this section, after which the results of the analysis will be presented together with the conclusions about them.

Genre, as a realization of the context of culture, refers to the overall purpose of a social interaction. Martin (1984: 25) describes genre as "a staged, goal-oriented, purposeful activity in which speakers engage as members of our culture". Genres have specific schematic and linguistic realizations, which are mediated through different text types or registers.

The context of situation or register refers to the immediate interactive situation and is therefore less abstract than the notion of genre. According to Halliday, the notion of 
context of situation can be interpreted by means of a conceptual framework using the terms field, tenor and mode of discourse, as the immediate environment in which a text is actually functioning. Halliday suggests that these three aspects of context show how we use language. In fact, it is here that we target the relationship between particular language choice and the specific context of situation in which it occurs. Field, tenor and mode are called register variables and a description of the values for each of these variables at a given time of language use is a register description of a text. As Halliday explains (1978: 111), although the register is intuitively recognizable as a specific lexicogrammatical configuration, "it is defined in terms of meanings" in such a way that "it is the selection of meanings that constitutes the variety to which a text belongs".

The field of discourse has to do with the focus of the activity in which we are engaged as recognized in the culture. It refers to what is happening, to the nature of the social action that is taking place, what the participants are engaged in, in which the language figures as some essential component (Halliday, 1989c: 30-31). Similarly, Gregory and Carroll (1978: 7) state that the field of discourse is the consequence of the user's purposive role, what his language is about, what experience he is verbalizing, what is going on through language. Sometimes field can be glossed as the topic of the situation but Martin's (1984: 23, 1992: 536) broader definition in terms of institutional focus, or social activity type is more useful to capture the field in situations where language is accompanying action.

The tenor of discourse is defined in terms of the players, the actors or rather the interacting roles that are involved in the creation of the text. It refers to who is taking part, to the nature of the participants, their status and role: what kinds of role relationship obtain among the participants, including permanent and temporary relationships of one kind or another, both the types of speech role that they are taking on in the dialogue and the whole cluster of socially significant relationships in which they are involved. This relationship that the speaker establishes with the audience in relation to the tenor of discourse has been emphasized by Gregory and Carroll (1978: 8) as well.

The general definition of mode refers simply to the role language is playing in the interaction. What it is that the participants are expecting the language to do for them in that situation: the symbolic organization of the text, the status that it has, and its function in the context, including the channel (if it is spoken, written or some combination of the two) and also the rhetorical mode, what is being achieved by the text in terms of such categories as persuasive, expository, didactic, and the like.

This model is functional and Halliday suggests that these components can be associated with three functional components or metafunctions: the experiential, the interpersonal and the textual, which are "the modes of meaning that are present in every use of language in every social context" (Halliday, 1978: 112). The relationship between the situation and the text is represented in Table 4.1.

In identifying these three strands of meaning Halliday is suggesting that of all the uses we make of language, language is intended to fulfil three main functions: a function for relating experience (experiential), a function for creating interpersonal relationships (interpersonal) and a function for organizing information (textual) (Eggins, 1994, 2004). 


\begin{tabular}{|c|c|c|}
\hline $\begin{array}{c}\text { SITUATION: } \\
\text { Feature of the context }\end{array}$ & (realized by) & $\begin{array}{c}\text { TEXT: } \\
\text { Functional component of semantic system }\end{array}$ \\
\hline $\begin{array}{c}\text { Field of discourse } \\
\text { (what is going on) } \\
\begin{array}{c}\text { Tenor of discourse } \\
\text { (who are taking part) }\end{array} \\
\begin{array}{c}\text { Mode of discourse } \\
\text { (role assigned to language) }\end{array}\end{array}$ & $\begin{array}{r}\text { Experiential meanings: } \\
\text { (transitivity, naming, etc.) } \\
\text { Interpersonal meanings: } \\
\text { (mood, modality, person, etc.) }\end{array}$ \\
\hline
\end{tabular}

Table 4.1. Relation of the text to the context of situation (Halliday, 1989b: 26).

Halliday points out that the field of the text can be associated with the realization ofexperiential meaning; these experiential meanings are expressed as patterns of transitivity through configurations of process (verbal group), participants (nominal group) and circumstance (adverbial group or prepositional phrase). The tenor of a text can be associated with the realization of interpersonal meanings; these interpersonal meanings are realized through the mood patterns of the grammar. And the mode of a text can be associated with the realization of textual meanings; these textual meanings are realized through the theme patterns of the grammar.

\section{Results of analysis}

I have already mentioned that news discourse is relevant to show the relationship between text and context. Unlike other types of discourse, its sensitiveness to both the social system and the social context makes it very convenient for analysis. This section examines these aspects more closely in reference to the data provided by news stories in The Times and The Sun, exploring the social context of the texts, the environment in which meanings are exchanged through the register variables that have a direct and significant impact on the type of news language that is produced, that is, field, tenor and mode of discourse. I will consider each register variable in detail, asking what they refer to, and in what ways each variable impacts on language use.

\subsection{Field and experiential meanings}

I have previously defined field as the situational variable that focuses on the activity in which we are engaged (Halliday, 1989a: 12; Martin, 1992: 536). Although field can be described as the topic of the situation, authors as Martin (1984:23, 1992: 536) glosses field in terms of institutional focus, or social activity type which is more useful to capture in situations where language is accompanying action. 
The effect of field on language use is an easy register variable to demonstrate convincingly. The description of the variable field in the corpus is "publishing (selling) newspapers, giving information and forming opinion about recent events of public interest" (Goatley, 1994: 160). To this description I have added the topic of situation, in the data collected what the news discourse is about. Considering the two selected texts from the corpus under analysis, we can see that both these news reports have the same field, that is, the fact that two British soldiers have been executed by Saddam Hussein's militiamen. It is obvious, however, that the situations which have given rise to each of these news stories are quite different. This may bring us to establishing the nature of these news items in relation to their cultural preferences within a particular stratum (Giles and Powesland, 1975; Giles, 1980). Following Halliday and Matthiessen's approach (2004), it should be recognized that situations may be either technical or everyday in their construction of an activity focus. In other words, field varies along a dimension of technicality (Eggins, 2004: 71). This activity focus is placed in news stories published in The Times differently from the ones published in The Sun, as it is schematized in Figure 5.1.

$\begin{array}{llll}\text { technical } & \text { The Times } & \text { The Sun } & \text { comonsense } \\ \text { specialized } & \text { (everyday) }\end{array}$

Figure 5.1. The field continuum in the corpus

As it is expected from the nature of the news stories in The Times and in The Sun, the process of assessment may be approached from the extremes where differences of both intention and resulting material are acute although, it must be said, such assessment is necessarily biased. The Times is widely regarded as a quality newspaper and it is possible to make some comments about it and why it should be regarded as such. Among people of reasonable education, there is a degree of consensus as to which are the quality newspapers. A newspaper may be said to have two main functions. Firstly, to inform and secondly to enlighten its readership about what is taking place, largely apart from the average reader's sphere of immediate apprehension.

In reference to the sample stories, it is clear that the intentions of the two newspapers differ. Coverage in The Times is much more detailed and extensive and it has a considerable amount of serious, informative and enlightening commentary in support of its main story. In this sense, The Times credits its readers with considerable powers of assimilation and sets out to inform them fully not only about what has occurred but also about a great deal of background and parallel material relevant to the news event. The Sun, however, accepts that its readers are interested in what has occurred and, apparently, that their power of concentration where such matters are concerned, is not great. The Sun's presentation compared to that of The Times is more segmented and broken up by headlines and photographs and in style it is much more anecdotal, nevertheless its reporting, attitude and supporting material are more serious in their approach. The intention in The Sun is clearly 
to entertain an audience assumed not to be interested in any but the most sensational world affair. Even intrinsically serious and potentially tragic themes are treated in this way. In saying this, it should be noted that the reference is to the intrinsic quality of the material and its presentation and not to such matters as methods of gaining information, moral attitudes, distortion or downright tying. Such things may or may not occur and may or may not be confined to the tabloids, but they are matters for another investigation.

To demonstrate that there are a number of linguistic implications to this variation in field, I will illustrate my explanation making reference to two news stories from the corpus published in The Times and The Sun on March 27 $7^{\text {th }}, 2003$ and transcribed in the appendix of this article.

Under the headline British bodies lie in dust as mob exults, The Times story is characterized by a heavy use of formal language, not just formal nouns but also verbs, as well as the use of acronyms. In this line, the following examples illustrate this assertion: nouns as distress, fatigues, coalition casualties, condemnation, status, breach, media outlets, campaign, networks, consensus, Geneva Convention. Verbs tend to be of technical processes or of attributive (descriptive) processes, as for example ambushed, deplore, request, dragged, condemned, undermine, aid and abet. Technicality is encoded in the use of acronyms as well, as $H Q$ (Headquarters), $R A F$ (Royal Air Force) or PoW (Prisoners of War). Apart from this, it is also worth mentioning that other news stories from the corpus reveal that this daily sometimes uses acronyms inaccessible to the layperson, since no explanation for the term is given as in $N A A F I$ (Navy, Army and Air Force Institutes), FDA (Food and Drugs Administration) or $N C U$ (National Communications Union).

The technical construction of the field in The Times is seen significantly different from the everyday language used in the news story published in the popular The Sun. Thus, The Sun story provides a clear example of how readers are moved towards the everyday understanding of the war. In fact, the story Saddam executes Our Boys is exactly the same as the story in The Times British bodies lie in dust as mob exults, except for the fact that the field has changed. Changing the field has a significant impact on the text, particularly on the content words used. Language in an everyday field as it is that in The Sun story is more familiar to us and the lexis tends to consist of everyday words. Note as an illustration the following terms from our data: outrage, tears, cold blood, grisly fate, slaughter, storm, brutality, ferocious battle, friendly fire, hot food, clean bedding, Cleopatra cigarettes. Verbs tend to be of the identifying (defining) kind (Eggins, 1994: 74), such as sickening, triggered, clambering, feared, slaughtered, wept, burned out, prayed, dashed, delighted, shipped, horrified. Acronyms are similarly used in The Sun's story as they are in The Times (TV, MoD (Minister of Defence), RAF, PoW). However, the data collected from the corpus show that whereas The Times uses acronyms on 42 occasions, acronyms in The Sun are only used if they are first introduced and then explained. In fact, its use is to a certain extent restricted to a few examples, being reduced to 25 occasions. This brief analysis provides a clear example of how these two newspapers use language in culturally recognized ways, demonstrating thus that the cultural context has an impact on language use.

The construction of the field of discourse can also be explored considering the 
transitivity patterns in the text. Transitivity establishes the functional role of the verb as process. Halliday (1985a) proposes four main process types, which encapsulate experiential meanings: material, mental, relational and verbal. Authors as Martin and Rothery (1981) suggest that patterns of process type contribute to the overall characterization of the text in terms of its genre, that is, they reflect the particular types of meanings being conveyed by the text. In this sense, recounts are characterized by material processes (of doing) as they tell about events, happenings, and where or when they occurred. By contrast, commentaries contain more mental (sensing) and relational (being and having) processes since they are concerned with personal attitudes and interpretations of events.

In this study, a transitivity analysis reveals that in selecting which process type to use the newswriter is actively choosing to represent experience in a particular way. Data show that newswriters represent the field of the situation in hard news stories mainly by the use of material processes, that is, describing processes of doing, usually concrete, tangible actions (discover, evacuate, explode, find, ban, etc.); and by means of verbal processes, processes of verbal action, by either quoting or direct speech and indirect or reported speech (announce, claim, deny, emphasize, indicate, point out, remark, say, tell, etc.). Although it is not my purpose here to concentrate on quoted and reported statements in the press as this is a rich and complex area, it should be mentioned in this discussion the presence of other process types (mental, relational) in the speech presentation in the form of direct or indirect report and quotation in The Times and The Sun as to meet the speaker's demands of representing the speech attributed to others (López Folgado, 2000; González Rodríguez, 2003, 2004). Note as an illustration the following extracts from the data to show how in selecting which process type to use newsmakers are actively choosing to represent experience differently in quality and popular newspapers. This variation is the result of a newswriting strategy which depends on communicative context; ultimately, interests, goals or ideological relevance in The Times and The Sun.

Group Captain Al Lockwood, the British spokesman in Qatar, said: "Showing pictures of dead soldiers and prisoners of war on television contravenes the Geneva Convention and we believe (al-Jazeera) are being irresponsible by showing them." (The Times, British bodies lie in dust as mob exults, March $27^{\text {th }} 2003$ )

Politicians also condemned the pictures of the dead men. A spokesman for Iain Duncan Smith, the Tory leader, said: "If it is confirmed that these two soldiers are British Service personnel, we find it deeply repellent that any television station has chosen to parade their bodies." Gerald Howarth, a Tory defence spokesman, said: "Iraq are brilliant at seeking to undermine the spirit of the coalition forces and if al-Jazeera has been aiding and abeting them it would be disgusting." (The Times, British bodies lie in dust as mob exults, March $27^{\text {th }}$ 2003)

Army spokesman Colonel Chris Vernon said: "We absolutely abhor the decision of $\mathrm{Al}$ Jazeera television to show dead prisoners of war. It totally contravenes all of the conventions of war and we condemn it completely." (The Sun, Saddam executes Our boys, March 27 2003 ) 
Tony Blair, who flew to the US last night for talks on the war with President George Bush, was "horrified" at the British deaths and that film of the victims were broadcast, his official spokesman said. (The Sun, Saddam executes Our boys, March $27^{\text {th }} 2003$ )

These differences in field between a formal and an everyday situation are summarized in Table 5.2.

Technical and everyday language: the linguistic implications of FIELD

\begin{tabular}{|l|l|}
\hline \multicolumn{1}{|c|}{ Technical language } & \multicolumn{1}{c|}{ Everyday language } \\
\hline technical terms & everyday terms \\
-words only "insiders" understand & -words we all understand \\
acronyms & full names \\
abbreviated syntax & standard syntax \\
technical action processes & identifying processes \\
attributive (descriptive) process & (defining terms) \\
\hline
\end{tabular}

Table 5.2. Technical vs. everyday language (Eggins, 1994; 74)

\subsection{Tenor and interpersonal meanings}

Tenor is referred to the relationship that exists between the interactants and their relative status and roles in the communicative situation. This variable is associated with the realization of interpersonal meanings, which in turn are influenced by the nature of the relationship: close or distant, and the formality of the communicative situation. Tenor expresses the participation or intrusion of the speaker/writer in the communicative situation through the expression of attitudes and judgements, and by seeking to influence the attitudes and behaviour of others.

Interpersonal meanings then are concerned with communication as interaction and how this is achieved. Claiming the link between language and context, Poyton (1985) has suggested that tenor can be broken down into three different continua: power, contact and affective involvement. The power continuum positions situations in terms of whether the roles we are playing are those in which we are of equal or unequal power. The contact continuum positions situations in terms of whether the roles we are playing are those that bring us into frequent or infrequent contact. And finally, the affective involvement continuum positions situations according to whether the roles we are playing are those in which the affective involvement between us is high or low.

In this context Eggins $(1994,2004)$ considers that we can draw a contrast between formal and informal situations, according to their typical tenor dimensions. In this framework, an informal situation typically involves interactants who are of equal power, who see each other frequently and who are affectively involved. In the formal situation, on the other hand, the power between the interactants is not equal, the contact is infrequent and the affective involvement is low.

Just as I did with field, so with tenor there are correlations between the dimensions of power, contact and affective involvement, and language patterns in hard news stories published in The Times and The Sun. Following this argument, Figure 5.2. summarizes these differences, which are discussed below. 

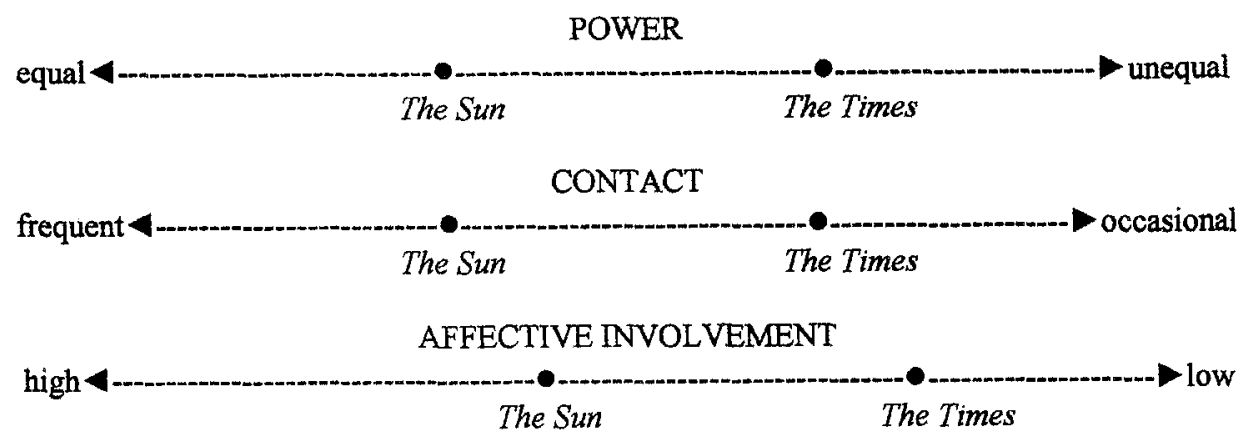

Figure 5.2. The power, contact and affective involvement continua in the corpus

As a matter of fact, the simultaneous dimensions power, contact and affective involvement have an impact on how newswriters use language in the quality The Times and in the popular The Sun. One major difference includes different vocabulary choices (typical in a formal vs. informal situation), as it was seen in the previous section. To this respect, news published in The Sun use words that express attitude. Attitudinal lexis can represent a positive or a negative evaluation, as the following lexical items from the news report Saddam executes Our Boys illustrate: clambering, slaughtered in cold blood, wept, grisly fate, abhor, ferocious battle, prayed, atrocity, delighted, horrified. The Times, however, expresses attitude in an apparently objective language, being an example of this the lexis in the news story British bodies lie in dust as mob exults: status, sombre, uncomfortable, flagrant, disgraceful, irresponsible, mistakenly. It should be also stressed that The Times tends to establish the formal situation using the complete lexical item (see, for example, television in the news given), while in informal settings the abbreviated forms of words are usually preferred ( $T V$ in the example story from The Sun).

Another area of interest that differentiates news stories in The Times from The Sun is that of vocatives (Poyton, 1984). Vocatives, or terms of address, are the words that people call each other when, for example, they wish to get each other's attention. Poyton's study of vocatives suggests that vocatives are a very potent area for the realization of interpersonal meanings and that there are correlations between the dimensions of power, contact and affective involvement, and the choice of vocatives. In this line, focusing upon the data provided by the corpus for this study we can come across remarkable contrastive variations.

In general terms, it could be argued that the type of interaction the reporter creates with The Sun reader is that where power is equal, contact is frequent and affective involvement is high. This situation explains the reciprocal vocative use: news actors may be called by their first name and it is usual to find diminutive forms of names, terms of endearment and nicknames. The reporter in The Times, however, establishes with the reader an unequal power, where the vocative use is non-reciprocal and, accordingly, news actors are called by their formal given names. 
The choice of vocatives in the corpus is briefly summarized in Table 5.3.

\begin{tabular}{|c|c|c|c|}
\hline \multirow{2}{*}{$\begin{array}{l}+ \text { informal } \\
\text { First name }\end{array}$} & \multicolumn{3}{|r|}{+ formal } \\
\hline & & & $\begin{array}{l}\text { Miss } / \mathrm{Mrs} / \mathrm{Mr} / \mathrm{Dr} / \mathrm{Sir} \text { (name) }+ \\
\text { surname }\end{array}$ \\
\hline & First name & Name + surname/surname & $\frac{\text { Miss/Mrs/Mr/Dr/Sir (name) }+}{\text { surname }}$ \\
\hline The Times & $0 \%$ & $54 \%$ & $46 \%$ \\
\hline The Sun & $12 \%$ & $61 \%$ & $27 \%$ \\
\hline
\end{tabular}

Table 5.3. The choice of vocatives in the corpus

I must point out that the limited choice of vocatives in this study is mainly due to the nature of the news items analysed, as they are events about the War on Iraq, which considerably reduces its possible use.

One further area in which tenor differences impact on language use concerns the grammatical systems of mood and modality. To this respect, another difference between news stories published in The Times and The Sun is found in headlines and it concerns the choice of clause structure to express interpersonal meanings. Certainly, the typical choice of clause mood in both publications is the declarative. Justification for this choice is formulated in terms of the basic communicative purpose of hard news stories as it is, purportedly, to inform and, more specifically, to convince the reader of the true values of the information supplied (van Dijk, 1988, 2001; Gamson, 2002). However, there are three cases in the data provided by The Sun in which this newspaper uses the imperative mood in its headline to signal the recognition of the equal power or frequent contact between the reporter and the reader, and to provide a realization of the dimension of affective involvement as well. Thus, by looking at these headlines one can uncover and understand the interpersonal relationships that are expressed in the popular newspapers:

- WHERE IS HE? (The Sun, April 10 2003 )

- Buried Alive (The Sun, April 16 2003 )

-TRAITOR! (The Sun, April 22 $2^{\text {nd }} 2003$ )

Apart from these differences, it is interesting to note finally that the news discourse in both newspapers tends to convey impersonality. As White (1997: 107) himself has claimed, hard news stories avoid:

explicit value judgements by the reporter about the morality, competence, normality, etc. of participants, explicit evaluations of events and entities in terms of their aesthetics or emotional impact, inferences about the motivations and intentions of participants and contentious claims 
about causes and effects [...] such meanings are either avoided or confined to the quoted comments of external sources in those canonical hard news texts which seek to represent themselves as neutral and impersonal.

However, I wish to argue here that far from being a mere collection of statements telling or describing facts interspersed with quoted or reported statements of opinion, the factuality of the discourse in both newspapers is more complex than that. To this respect, the corpus for this study provides data to argue that the factual vs. non-factual dichotomy claimed for newspaper reports is a too rough division and that subjective opinions in newspaper writing come up under the structural frame of statements describing an actual situation (Ungerer, 2000: 156; Gamson, 2002: 187-198). Thus, White (1997: 108-109) himself makes this remark:

A recurring feature of the hard news report is the presence of lexis which encodes a sense of intensity or heightened involvement by the author and which positions the reader to view the events or statements described as significant, momentous or emotionally charged [...] this intensification [...] most typically takes two forms:

Lexis, which combines an informational meaning with a sense of interpersonal engagement and heightened impact $[\ldots]$

Comparisons, which assert the great size, force, severity, significance, etc. of the action under consideration $[\ldots]$

\subsection{Mode and textual meanings}

The general definition of mode refers to the role language is playing in the interaction. Martin (1984) has suggested that this role involves two simultaneous continua which describe two different types of distance in the relation between language and situation: the spatial or interpersonal distance and the experiential distance.

The spatial or interpersonal distance ranges situations according to the possibilities of immediate feedback between the interactants. At one pole of the continuum, then, it is the situation of sitting down to a casual chat with friends, where there is both visual and aural contact, and thus feedback is immediate. At the other end of the continuum it would be the situation of writing a book, where there is no visual or aural contact between writer and reader(s), and no possibility of immediate feedback.

The experiential distance ranges situations according to the distance between language and the social process occurring. At one pole of this continuum Martin puts situations such as playing a game (of cards, monopoly, etc.), where language is being used to accompany the activity interactants are involved in. The role of language in such a situation is one of the means being used to achieve on-going action. At the other polar extreme is the situation, for example, of writing a piece of fiction, where language is being used to reflect on experience, rather than to enact it.

As Table 5.4. shows, combining these two dimensions of mode the basic contrast between spoken and written situations of language use can be characterized. 


\begin{tabular}{|c|c|}
\hline Spoken discourse & Written discourse \\
\hline $\begin{array}{l}\text { +interactive } \\
2 \text { or more participants } \\
\text { + face-to-face } \\
\text { in the same place at the same time } \\
\text { + language as action } \\
\text { using language to accomplish some task } \\
\text { + spontaneous } \\
\text { without rehearsing what is going to be said } \\
\text { + casual } \\
\text { informal and everyday }\end{array}$ & $\begin{array}{l}\text { non-interactive } \\
\text { one participant } \\
\text { not face-to-face } \\
\text { on his/her own } \\
\text { not language as action } \\
\text { using language to reflect } \\
\text { not spontaneous } \\
\text { planning, drafting and rewriting } \\
\text { not casual } \\
\text { formal and special occasions }\end{array}$ \\
\hline
\end{tabular}

Table 5.4. Characteristics of spoken/written situations (based on Eggins, 1994: 55)

These characteristics of the spoken and written situations point out significant aspects about how language is used. As it can be seen, "1e same content, the same set of actions and events in the real world, get related in two very different linguistic forms according to whether we are speaking or writing. Bearing this in mind, I will end this section with a discussion on these dimensions of the situation and their effect on the language used in quality and popular hard news stories.

Describing the spatial or interpersonal distance, the examples from the corpus I have presented throughout the paper consist of daily newspaper discourse. These articles would be in a situation similar to writing a book, without any contact between newswriter and reader, although in the case of newspaper reports there is a limited possibility of delayed feedback. In this sense, the national newspapers have procedures for dealing with readers' complaints. Apart from that, another possibility of delayed feedback could be related to the varying proportions from sales accounts.

Taking the end points of the continuum of experiential distance, writing a report in a newspaper is placed, as Martin illustrates (1984: 27), in an intermediate position between the two poles. That is, between a situation where language is used to reflect on experience, creating and constituting the social process, and that where language involves a typically interactive situation.

There are some implications of the contrast between the spoken and written mode in the corpus analysed. Thus, certain linguistic patterns correspond to different positions on the mode continua. The Times is closer to the written pole of the variable mode, and it is characterized by the choice of prestige lexis and by the use of standard grammatical conventions. By contrast, The Sun contains everyday words, an echo of daily situations and the language is mainly concerned with human actions. News reports are positioned at the spoken pole of the continuum by means of elections of actions, thoughts and feelings.

The two situations of language use can be summarized as shown in Figure 5.3. 


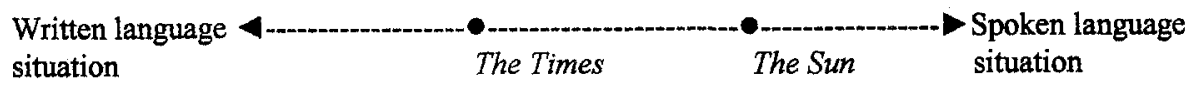

Figure 5.3. The mode continuum in the corpus

A rough analysis such as the one carried out in this section yields interesting insights as to the nature of how language is used in The Times and The Sun. However, I would suggest the need for further research into this area. For a more exhaustive treatment, there are two more linguistic features that are highly sensitive to mode variation and are responsible for striking differences between spoken and written language. These are the degree of grammatical complexity and the lexical density of the language chosen, both of which are related to the process of nominalization. In this way, these factors may be worth taking into account in order to arrive at a better insight into this phenomenon and into the nature of language variation in newswriting.

\section{Concluding Remarks}

This article has offered a critical description of the influence of social and cultural context on the linguistic patterns of news stories in The Times and The Sun, two British national newspapers that belong to different cultural idiosyncrasies. In order to account for the contextual features of the news analysed, I have studied how texts are coherent in terms of their context of situation through the notion of register, taking Halliday's An Introduction to Functional Grammar (1985a, 1994) and Halliday and Matthiessen's (2004) as its base.

Data obtained from the study on the linguistic structures used in hard news stories in quality and popular British newspapers have been correlated with the three register variables of field, tenor and mode, with the aim of illustrating to what extent situational factors determine and influence the linguistic features used in this variety. The results obtained have shown that in newswriting the relationship between form and social function is very obvious. To this respect, most of the language choices are explained in connection with situational factors of the specific context of situation for each text. Furthermore, as we have seen, when the same selection of meanings occurs in news stories from different types of newspapers, their ways of expression present variations. These variations are caused by differences in the range of options of their respective meaning potentials. In this regard, Halliday (1973: 45) summarizes the importance of the linguistic study of texts as a way of understanding how language functions in its immensely varied range of social contexts, when he observes that:

When we interpret language in these (functional-semantic) terms we may cast some light on the baffling problem of how it is that the most ordinary uses of language, in the most everyday situations, so effectively transmit the social structure, the values, the systems of knowledge, all the deepest and most pervasive patterns of the culture. With a functional 
perspective on language, we can begin to appreciate how this is done.

Considering Halliday's reflection, I believe that the approach I have brought along here from an integrated perspective, without splitting apart the linguistic study of texts from aspects of language in use, could be an outstanding overall means to know more about different types of news texts in relation to culture-bound features (Halliday, 1994: xv; Renkema, 2004: 46). Overall, this study has argued in favour of viewing language as a social semiotic resource people use to accomplish their purposes by expressing meanings in context. "The value of a theory", Halliday wrote, "lies in the use that can be made of it, and I have always considered a theory of language to be essentially consumer oriented" (1985b: 7). And I hope to have shown this.

\section{References}

Allan, Stuart (2004): News Culture. Maidenhead: Open UP.

Bell, Allan (1991): The Language of News Media. Oxford: Blackwell.

Bloor, Thomas and Meriel Bloor (1995/2004): The Functional Analysis of English: A Hallidayan Approach. London: Arnold.

Chafe, Wallace (2003): "The analysis of discourse flow". In Deborah Schiffrin, Deborah Tannen and Heidi E. Hamilton, eds., The Handbook of Discourse Analysis. Oxford: Blackwell, 673-687.

Dijk, Teun A. van (1988): News as Discourse. Hillsdale, NJ: Erlbaum. . (2001): "Critical discourse analysis". In Deborah Schiffrin, Deborah Tannen and Heidi E. Hamilton, eds., The Handbook of Discourse Analysis. Malden, Mass: Blackwell, 352-371. Eggins, Suzanne (1994): An Introduction to Systemic Functional Linguistics. London: Pinter Publishers.

. (2004): An Introduction to Systemic Functional Linguistics (Second Edition). London: Continuum.

Fairclough, Norman (1995): "Communication in the mass media". Media Discourse. London: Edward Arnold, 35-53.

. (1998): "Political discourse in the media: An analytical framework". In Allan Bell and Peter Garrett, eds., Approaches to Media Discourse. Oxford: Blackwell, 142-162.

Gamson, William A. (2002): "How storytelling can be empowering." In K. Cerulo, ed., Culture in Mind: Toward a Sociology of Culture and Cognition. New York: Routledge, 187-198.

Ghadessy, Mohsen (ed.) (1999): Text and Context in Functional Linguistics. Amsterdam: Benjamins.

Giles, Howard and Peter F. Powesland (1975): Speech Style and Social Evaluation. London: Academic Press.

Giles, Howard (1980): "Accommodation theory: Some new directions". York Papers in Linguistics 9: 105-136.

Goatley, Andrew (1994): "Register and the redemption of relevance theory". Pragmatics 4/2: 139-182.

Gómez Guinovart, Javier and Javier Pérez Guerra (2000): "A multidimensional corpus-based analysis of English spoken and written-to-be spoken discourse". Cuadernos de Filología 
Inglesa $9.1: 39-70$.

González Rodríguez, María José (2003): “Relaciones lógico-semánticas y su forma de expresión en el género noticia". Atlantis 25(2): 55-69.

. (2004): "Proyección en el género noticia: Funciones y uso de los estilos directo e indirecto". Revista de Lingüística Teórica y Aplicada 42(2): 107-121.

Gregory, Michael and Susanne Carroll (1978): Language and Situation: Language Varieties and their Social Contexts. London: Routledge and Kegan Paul.

Haan, Pieter de (1987): Noun Phrase Complexity and Language Variation. Corpus Linguistics and Beyond. Amsterdam: Rodopi.

Halliday, Michael A.K. (1973): Explorations in the Functions of Language. London: Arnold. . (1978): Language as a Social Semiotic: The Social Interpretation of Language and Meaning. London: Arnold.

. (1985a): An Introduction to Functional Grammar. London: Arnold.

. (1985b): "Systemic background". In James D. Benson and William S. Greaves, eds., Systemic Perspectives on Discourse. Selected Theoretical Papers from the $9^{\text {th }}$ International Systemic Workshop. Volume I. Norwood, NJ: Ablex Publishing Corporation, 1-15.

(1989a): "Context of situation". In Michael Halliday and Ruqaiya Hasan, eds., Language, Context, and Text: Aspects of Language in a Social-Semiotic Perspective. Oxford: Oxford University Press, 3-14.

. (1989b): "Functions of language". In Michael Halliday and Ruqaiya Hasan, eds., Language, Context, and Text: Aspects of Language in a Social-Semiotic Perspective. Oxford: Oxford University Press, 15-28.

. (1989c): "Register variation". In Michael Halliday and Ruqaiya Hasan, eds., Language, Context, and Text: Aspects of Language in Social-Semiotic Perspective Oxford: Oxford University Press, 29-43.

. (1994): An Introduction to Functional Grammar (Second Edition). London: Arnold.

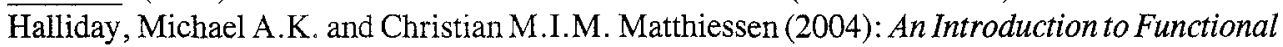
Grammar (Third Edition). London: Arnold.

López Folgado, Vicente (2000): "Projection in news discourse: Speech responsibility and attitude". Revista Canaria de Estudios Ingleses 40: 189-207.

López Maestre, María Dolores (1997a): "Complexity in the headlines of The Times (1970-1990)". In Santiago Fernández-Corugedo, ed., Some Sundry Wits Gathered Together. Coruña: Servicio de Publicación Universidade da Coruña, 107-115.

. (1997b): "Is there any stylistic variation within the headlines of a single newspaper?: A study of the intranewspaper variation of the grammar of the headlines in six sections of The Times (1970-1990)". Estudios de Lingüistica Aplicada y Literatura: Homenaje póstumo al profesor Juan Conesa Sánchez. Murcia: Servicio de Publicaciones de la Universidad de Murcia, 155-166.

. (1998): "Noun phrase complexity as a style marker: An exercise in stylistic analysis". Atlantis XX.2: 91-105.

. (1999): "Interrelación de factores sociales y estructura gramatical en una variedad de lenguaje: Un estudio de estilística". Revista Canaria de Estudios Ingleses 39: 251-274.

Mardh, Ingrid (1980): Headlines on the Grammar of English Front Page Headlines. CWK Gleerup Lund Studies in English.

Martin, James R. (1984): "Language, register and genre”. In Frances Christie, ed., Children 
Writing: Reader, Geelong, Vic.: Deakin University Press, 21-29. . (1992): English Text: System and Structure. Amsterdam: Benjamins.

Martin, James R. and John Rothery (1981): Writing Project Report: Working Papers in Linguistics 2. Linguistics Department, Sydney University.

Martin, James R. and D. Sharma Rose (2003): Working with Discourse: Meaning Beyond the Clause. London: Continuum.

Poyton, Cate (1984): "Names as vocatives: Forms and functions". Nottingham Linguistics Circular 13: 1-34.

. (1985): Language and Gender: Making the Difference. Geelong, Vic.: Deakin University Press.

Renkema, Jan. (2004): Introduction to Discourse Studies. Amsterdam: Benjamins.

Simon- Vanderbergen, Anne M. (1981): The Grammar of Headlines in The Times 1870-1970.

Brussels: Paleis der academiën-hertogsstraat I.

Sperber, Dan and Deirdre Wilson (1995): Relevance. Communication and Cognition. Oxford: Blackwell.

Thompson, Robert G. (1996): Introducing Functional Grammar. London: Arnold. . (2004): Introducing Functional Grammar (Second Edition). London: Arnold.

Ungerer, Friedrich (ed.) (2000): English Media Texts, Past and Present. Language and Textual Structure. Amsterdam: Benjamins.

White, Peter R.R. (1997): "Death, disruption and the moral order: The narrative impulse in mass

media 'hard news' reporting". In Christie F. and James R. Martin, eds., Genre and Institutions: Social Processes in the Workplace and School. London: Cassell, 100-133.

\title{
APPENDIX
}

\author{
TRANSCRIPTION OF THE NEWS ITEMS \\ PUBLISHED IN THE TIMES AND THE SUN ON MARCH $27^{\text {th }}, 2003$
}

\section{The Times, March $27^{\text {th }}, 2003$}

\section{British bodies lie in dust as mob exults}

\section{BY DAVID CHARTER AND ALAN HAMILTON}

THE images are gruesome and calculated to cause the utmost distress. Two dead and bloodstained soldiers in unmarked desert fatigues lie side by side on a dusty road. For a while yesterday there was doubt about their identity or even whether they were genuine coalition casualties. Now we know they are British.

Al-Jazeera, the Qatar-based television station repeatedly showed yesterday afternoon a 30 second sequence which no one here will wish to see. The station said the pictures were recorded on Tuesday in al-Zubayr near Basra. 
British sources in Qatar said last night that the footage showed the bodies of two soldiers attached to the Desert Rats missing in action since their Land Rover was ambushed by Iraqi forces on Sunday. The footage brought immediate condemnation from British commanders and politicians, and tears to the eyes of the dead men's comrades in the Gulf who saw it.

Relatives of the two men were being informed that their status was being changed to "missing believed killed" pending formal identification.

In the same brief sequence the Arab-language satellite channel showed images of the two hostages looking sombre and uncomfortable. Both men were black, one in his 40s and the other much younger and wearing dreadlocks. Behind them a group of animated Iraqis held up finders in V-for-victory signs.

Unlike Sunday's al-Jazeera footage taken from Iraqi state television which claimed to show a group of American prisoners-of-war, there was this time no audio, no attempt to push a microphone in the men's faces and question them.

Their voices were not heard, and their clothes betrayed no identity. UK National Contingent HQ do not believe the two hostages are British.

Al Jazeera also showed shots of a crowd surrounding and dancing overturned Land Rover and its trailer with a British military numberplate. The station also showed pictures of what appeared to be a broken Phoenix spotter drone with RAF insignia, of the type used by the Royal Artillery to spot targets.

Senior British figures are furious at al-Jazeera's decision to screen the pictures, particularly those of the dead men which will be widely seen throughout the Arab world. A Ministry of Defence spokesman describing it as a flagrant and disgraceful breach of the Geneva Convention said: "We deplore the decision by al-Jazeera to broadcast such material and call up them to desist immediately. We request all other media outlets not to become tools for Iraqi propaganda by rebroadcasting such material."

Commanders are only too well aware of the damaging psychological effect such images can have if seen back home. They well remember during the last Gulf War, the parading of the British pilots John Peters and John Nichol, looking extremely battered and bruised, on Iraqi television.

Other coalition pilots from Italy and the US were also seen during that conflict, forced to read out pro-Iraqi propaganda on Iraqi television.

But all will remember even more keenly the images from Somalia in 1993, when the corpses of US soldiers were dragged triumphantly through the streets of Mogadishu. It was not long after those deeply disturbing images had been seen in America that the troops were brought home.

Group Captain Al Lockwood, the British spokesman in Qatar said: "Showing pictures of dead soldiers and prisoners of war on television contravenes the Geneva Convention and we believe (alJazeera) are being irresponsible by showing them."

He admitted that the coalition had mistakenly allowed images of PoWs to be filmed. "We had one or two mistakes early on in the campaign when enemy PoWs were shown on UK networks. There has been a general consensus that it is a violation of the Geneva Convention and they will no longer do it."

Politicians also condemned the pictures of the dead men. A spokesman for Iain Duncan Smith, the Tory leader, said: "If it is confirmed that these two soldiers are British service personnel, we find it deeply repellent that any television station has chosen to parade their bodies." Gerald Howarth, a Tory defence spokesman, said: "Iraq are brilliant at seeing to undermine the spirit of the coalition forces and if al-Jazeera has been aiding and abetting them it would be disgusting." 
The Sun, March $27^{\text {th }}, 2003$

\section{Saddam executes Our Boys}

From NICK PARKER in southern Iraq and GEORGE PASCOE-WATSON in Qatar

SICKENING TV film showing two executed British soldiers lying in a dusty Iraqi street triggering outrage and tears last night.

The Arab station Al Jazeera broadcast pictures taken by Saddam Hussein's Fedayeen militiamen minutes after they killed the pair, both Desert Rats.

One trooper had a massive chest wound and the other's neck and upper chest was covered in blood.

Both men's faces were clearly visible on the film - shot at close range in the border town of Safwan.

Nearby, dozens of Iraqi militiamen were seen clambering over the soldier's overturned Land Rover.

It is feared the pair were ambushed, pulled from the vehicle and slaughtered in cold blood.

Last night the dead men's comrades, who hoped they had saved themselves after they went missing on Sunday, wept when told of their gristy fate.

And they were furious that the Iraqi regime had passed the film footage to the TV station.

Army spokesman Colonel Chris Vernon said: "We absolutely abhor the decision of Al Jazeera television to show dead prisoners of war. It totally contravenes all of the conventions of war and we condemn it completely."

A British military source said of the slaughter: "Such barbarism reflects the true nature of the Iraqi regime. We're witnessing the lowest conceivable standards of decency and humanity."

The storm over the televised brutality dominated Day Seven of the war, which also saw:

UP to 1000 Iraqi soldiers killed by US forces in a ferocious battle at Najaf.

A DEVASTATING RAF attack on 120 Iraqi tanks and armoured vehicles trying to break out of Basra.

PREPARATIONS for a massive head-on confrontation between US Marines and 5,000 Republican Guard troops on Iraq's Highway Seven.

AT least 14 Iraqis killed by two stray Allied bombs that fell on a market of Baghdad.

US troops taking control of the city of Nasiriya, but with the loss of ten Marines, and

THE naming of two British tank crewmen killed by "friendly fire" from another Army Challenger.

The dead Britons shown on TV are thought to have been attached to an artillery regiment of the Desert Rats.

Their Land Rover was in a convoy of ten vehicles, including Warrior armoured personnel carriers, ambushed by militiamen using rocket-propelled grenades.

In a well-drilled reaction, the convoy dispersed to prevent the enemy from having a large target. The pair were declared missing after the formation regrouped without them.

Hours later comrades found their upturned vehicle, which had been partially burned out.

They prayed the duo had managed to embark on an escape and evasion exercise. But last night's TV pictures dashed any such hopes.

The Ministry of Defence last night made a formal request to $\mathrm{Al}$ Jazeera to stop showing the film. 
The Sun has respected the MoD's wishes by not publishing the pictures.

But the station, which also showed footage of a downed unmanned RAF spy drone, refused to comply.

There were fears the victims' families would see the video if other cable networks picked it up. And MoD chiefs tried to contact the relatives to pass on news of the tragedy.

The deaths took the number of British servicemen killed or missing in action to 22 .

As news broke of the Fedayeen atrocity, it was revealed Iraqi prisoners are being well looked after by British forces.

A clean, well-organised PoW centre has been established for 2,000 captives in the port town of Umm Qasr.

Soldiers given the task of guarding the men toid how many were delighted to be getting hot food, drinks and clean bedding.

Allied commanders have even shipped in creature comforts for their captives $-72,000$ of their favourite Cleopatra cigarettes.

Tony Blair, who flew to the US last night for talks on the war with President George Bush, was "horrified" at the British deaths and that film of the victims were broadcast, his official spokesman said.

The PM's plane was hit by lightning as it approached the US. There were no injuries or damage. 